\title{
COMPARISON OF VOLUMETRIC SHRINKAGE OF COMPOSITE RESIN NANOCERAMIC AND
} NANOFILLER

\author{
BANI IMRAN MASULILI ${ }^{1}$, ENDANG SUPRASTIWI ${ }^{2 *}$, DEWA AYU NYOMAN PUTRI ARTININGSIH ${ }^{2}$, \\ CATERIN NOVISTA ${ }^{1}$
}

${ }^{1}$ Department of Conservative Dentistry, Residency Program, Faculty of Dentistry, Universitas Indonesia, Indonesia. ${ }^{2}$ Department of Conservative Dentistry, Faculty of Dentistry, Universitas Indonesia, Indonesia. Email: esuprastiwi@yahoo.co.id

Received: 08 July 2019, Revised and Accepted: 29 April 2020

ABSTRACT

Objective: The main cause of failure of composite resin restorations is volumetric shrinkage. The aim of this study was to analyze and compare volumetric shrinkage in nanohybrid and nanoceramic composite resins.

Methods: A total of $32(3 \mathrm{~cm} \times 3 \mathrm{~cm} \times 2 \mathrm{~mm})$ cavities were analyzed for volume using micro-CT. The samples were divided randomly into two groups: 16 cavities that were restored using nanohybrid composite resin and 16 cavities that were restored using nanoceramic composite resin. The composite resin volume was analyzed using micro-CT.

Results: The difference in volumetric shrinkage between nanohybrid composite resin 245,866.5 $\mathrm{mm}^{3}$ (3\%) and nanoceramic composite resin $3,470,175.13 \mathrm{~mm}^{3}(5 \%)$ was not significant $(\mathrm{p}=0.585)$.

Conclusion: Nanohybrid and nanoceramic composite resins have the same volumetric shrinkage rate.

Keywords: Composite resin, Nanohybrid, Nanoceramic, Volumetric shrinkage.

(C) 2020 The Authors. Published by Innovare Academic Sciences Pvt Ltd. This is an open access article under the CC BY license (http://creativecommons. org/licenses/by/4. 0/) DOI: http://dx.doi.org/10.22159/ijap.2020.v12s2.0P-02

\section{INTRODUCTION}

One of the disadvantages of composite resin is the volumetric shrinkage that occurs at the time of the polymerization that causes attraction in the interface between the cavity wall and the composite resin. This can cause adhesion failure, the formation of microleakage that can create sensitivity after restoration, and secondary caries [1]. Factors influencing volumetric shrinkage during polymerization are filler particles, degree of conversion, elastic modulus, water absorption, thermal expansion coefficient, light intensity, and cavity configuration factor (factor-C) [2].

To reduce volumetric shrinkage during polymerization, the proportion of monomers and filler particles is changed by adding more fillers and less resin Sandelin B, Afaag, 2015 [3]. Nanosized filler particles are currently being developed to minimize shrinkage, improve mechanical properties, and increase wear resistance [4]. In 2003, nanoceramic composite resin began to be combined with methacrylate-modified polysiloxane, with $76 \%$ of the total weight being glass particles with a size of 1.1-1.5 $\mu \mathrm{m}$. To increase, mechanical strength is combined with polyurethane-methacrylate and also bis-EMA and TEGDMA. Combining this photoinitiator system increases the durability of the methacrylate resin matrix. Nanoceramic filler particles are spherical mixtures and pre-polymerized SphereTEC ${ }^{\mathrm{TM}}$, which contain barium non-agglomerated glass and ytterbium fluoride with filler loads ranging from $77 \%$ to $79 \%$ by weight $(59 \%-1 \%$ by volume) [5].

The main difference between nanohybrid and nanoceramic composite resins is that nanohybrid composite resins have an irregular filler particle shape, whereas nanoceramic composite resins are spherical and contain both large and small submicron particles so that the gap filled with matrix is reduced and there is less polymerization shrinkage. The authors are interested in conducting this study because they want to know, whether nanohybrid and nanoceramic composite resins undergo volume shrinkage during polymerization and whether the two composite resins differ in terms of volume shrinkage. We analyzed and compared the volumetric shrinkage of nanoceramic and nanohybrid composite resins. Our reasons for doing so are explained in this paper.

\section{METHODS}

Sixteen extracted premolar teeth were cleaned under running water. Cavities with a depth of $3 \mathrm{~mm}$, a buccolingual width of $3 \mathrm{~mm}$, and a gingival wall width of $2 \mathrm{~mm}$ were made on the mesial and the distal sides of the teeth using a cylindrical diamond bur.

Each cavity was numbered and, before being filled with composite resin, was analyzed in respect of volume using a micro-computed tomography (CT) SkyScan 1173 (Bruker, Belgium) device at a high-resolution level (1 pixel $=29.8$ micrometers $), 130 \mathrm{kV}, 60 \mathrm{Ma}$, and $0.1^{\circ}$ rotation step. The scan lasts $5 \mathrm{~h}$. All slices were then reconstructed using NRecon and Data Viewer software (Bruker, Belgium) and analyzed using the CT analyzer (CT-An) (Bruker, Belgium). All cavity samples were divided into two groups, each consisting of 16 cavities. In Group I, the teeth were restored using nanohybrid composite resin (IPS Empress, Ivoclar Vivadent) to $3 \mathrm{~mm}$ depth, whereas, in Group II, the teeth were restored using nanoceramic composite resin (Ceram-X, SphereTEC ${ }^{\mathrm{TM}}$ Dentsply) to $3 \mathrm{~mm}$ depth.

Before being filled with composite resin, all cavity samples had the same adhesive system, Single Bond 2 (3M-ESPE), applied using a micro-brush, according to the manufacturer's protocol. Composite resin was added in increments by placing the first layer at a slant on one of the upright walls, followed by polymerization for $20 \mathrm{~s}$, then placing the next layer at a slant on the other wall, followed by polymerization for $20 \mathrm{~s}$, and finally using the last layer to fill the remaining space up to the surface of the cavity. This was followed by finishing and polishing. Then, the volume of composite resin was measured using micro-CT and CT-An. The samples were scanned with SkyScan 1173 micro-CT (Bruker, Belgium) at high resolution (1 pixel $=29.8$ micrometers), $130 \mathrm{kV}, 60 \mathrm{Ma}$, and rotation steps of $0.1^{\circ}$. 
Table 1: Mean value, standard deviation, and the significance of cavity, nanohybrid and nanoceramic composite resin volumes (mm ${ }^{3}$ )

\begin{tabular}{lllll}
\hline Groups & N & Mean & Differences & SD \\
\hline & & & & \\
Cavity volumes & 16 & $1,619,314.44$ & $245,866.5$ & $227,865.524$ \\
Nanohybrid CR volumes & 16 & $1,373,447.94$ & $(3 \%)$ & $197,665.646$ \\
& & & & \\
Cavity volumes & 16 & $1,645,264.94$ & $3,470,175.13$ & $195,901.349$ \\
Nanoceramic CR volumes & 16 & $1,275,089.81$ & $(5 \%)$ & $361,575.192$ \\
\hline
\end{tabular}

*t-test; $\mathrm{p}<0.05$ significant

The scan lasts for $5 \mathrm{~h}$. This scanning reconstruction became sliced with the help of NRecon and DataViewer software (Bruker, Belgium) and analyzed using CT-An (Bruker, Belgium). Data on the cavity volume and the volume of the composite resins were analyzed using parametric statistical tests with SPSS 23. Normal data distribution was obtained using the normality distribution test and further testing with t-test was proceeded.

\section{RESULTS AND DISCUSSION}

The results of the study were carried out statistical analysis using an independent T-Test to study differences between groups, with a significance limit of $\mathrm{p}=0.05$.

Table 1 shows that the differences in mean values between cavity groups and composite resin groups decreased with both nanohybrid (3\%) and nanoceramic (5\%) composite resins. The differences showed a significance of $p \leq 0.005$. Table 2 shows that volumetric shrinkage values show that there were no significant differences between nanohybrid and nanoceramic composite resins $(\mathrm{p}>0.005)$

The volumetric shrinkage during polymerization of composite resins is between $1.8 \%$ and $5.0 \%$, and it is often associated with failure of marginal adaptation [6]. The reason for this is that, during polymerization, double bonds between carbon molecules will be converted to single bonds, reducing the distances between molecules. Han (2012) and Anusavice (2013) stated that during the polymerization of composite resin into a dense structure, shrinkage can cause stress, fissures, discoloration, secondary caries, cracks, and increased sensitivity. Using more filler and less monomer, the polymerization shrinkage can be reduced [7]. In this study, the differences in volume shrinkage between nanohybrid composite resin and nanoceramic composite resin were analyzed because these two types of composite resins have filler particles of different sizes and shapes.

Polymerization shrinkage is known to be related to organic and inorganic components of composite resins [8]. Factors that influence polymerization shrinkage include filler components, matrix, and C-factor [6]. According to Han (2010), using more fillers and fewer monomers should reduce polymerization shrinkage. Shrinkage of composite resin can range from $1.67 \%$ to $68 \%$ of the total restoration volume [9]. According to Braga RR, Ferracane JL, 2004 [6], the volume of polymerization damage in composite resins is from $2 \%$ to $6 \%$ [6]. Polymerization shrinkage in restoration with a high $\mathrm{C}$-factor $(\mathrm{C}=5)$ will produce high polymerization stress as the flow capability of the composite resin is limited [9]. The fewer the restorations attached to the cavity wall, the fewer the contractions. The previous studies have shown that polymerization stress magnitude is influenced by the characteristics of the cavity configuration or C-factor is defined as the ratio of the bonded to the unbonded surface area. There is considerable plastic deformation when polymerization occurs before the gelation point is reached.

The first type of composite resin tested in this study was a nanohybrid composite resin containing two forms of particles: Single nanomeric particles and nanocluster particles. Nanoclustering unites nanomeric oxide to form a collection of particles measuring 5-75 $\mathrm{nm}$. The second type of resin tested was a nanoceramic composite resin made using
Table 2: Median, minimum, maximum, and significance values between groups of nanohybrid and nanoceramic composite resins $\left(\mathrm{mm}^{3}\right)$

\begin{tabular}{lllll}
\hline $\begin{array}{l}\text { Composite } \\
\text { resin }\end{array}$ & n & Median & Min-Max & p \\
\hline & & & & 0.585 \\
Nanohybrid CR & 16 & $1,325,733.50$ & $105 \mathrm{E}+6-173 \mathrm{E}+6$ & \\
Nanoceramic CR & 16 & $1,328,762.00$ & $168,868.00-175 \mathrm{E}+11$ & \\
\hline $\mathrm{p}<0.05$ significant & & & &
\end{tabular}

nanoparticle technology with a modified resin matrix. The nanoparticle methacrylate-modified polysiloxane is made from a ceramic particle granulation spray. In this study, sample analysis used direct visual representation techniques with micro-CT. This technique was used because it was non-invasive, accurate, and reproducible. Another advantage of this method is that it decreases the possibility of operator bias when interpreting the filler form and can thus improve physical, mechanical, optical, and clinical properties of the filler $[6,10]$.

Differences in mean values between the cavity group and the nanohybrid and nanoceramic composite resin groups are shown in table 1 . The difference between the volume of cavities and the volume of nanohybrid composite resin was $3 \%$, whereas it was $5 \%$ for nanoceramic composites; these differences have significant values. Sarangi et al. (2014)'s findings indicated that polymerization shrinkage of Ceram-X (2.3\%) was higher than that of Tetric N-Ceram (2.09\%) [9]. The difference in volumetric shrinkage between dimethacrylate-based nanohybrid composite resin and nanoceramic composite resin ranges from $2 \%$ to $6 \%$ [11]. This difference occurs because the matrix type of nanohybrid composite resin consists of conventional monomers such as Bis-GMA (bisphenol A-glycidyl methacrylate), whereas the nanoceramic composite resin matrix consists of glass particles of $1.1-1.5 \mu \mathrm{m}$ in size that make up $59 \%-61 \%$ of the total volume. Nanoceramic composite resin has a matrix of methacrylatemodified polysiloxane resin. Nanohybrid composite resins contain filler material of different particle sizes. This difference in filler size causes the distribution of homogeneous fillers in the matrix. This composite contains two forms of nanoparticles: Single nanomers and nanoclusters. Single nanomers are individual particles that are generally round in shape and are usually $1 \mu \mathrm{m}$ in size. Nanoclusters are collections of single nanomers that range in size from 2 to $20 \mathrm{~nm}$. The filler particles can reach $69 \%$ by volume and $84 \%$ by weight, reducing shrinkage during polymerization $[12,13]$. Polymerization shrinkage is particularly common in high C-factor restoration and may be increased with the use of high modulus composites, as they may transmit greater polymerization shrinkage force to the tooth. The current study used Class I cavities with high C-factor restoration [9].

In Table 2, analysis of the differences in the volume of nanohybrid composite resin and nanoceramic composite resin shows that there were no significant differences ( $p>0.05)$, indicating that the two composite resins have the same volume of polymerization shrinkage. The nanohybrid composite resin contains approximately $57 \%$ (volume) inorganic fillers with an average particle size of 0.4 
microns, whereas nanoceramic composite resins have a total filler content of 59\%-61\% (volume). Thus, nanohybrid and nanoceramic composite resins have similar total volumes of fillers. According to Julian et al., the shrinkage stress value is generally lower for composites with spherical filler particles than for those with irregular filler particles [13].

\section{CONCLUSIONS}

Although the technology used in making nanoceramic and nanohybrid composite resins differs, both composite resins undergo volume shrinkage during polymerization. The volume shrinkages of the nanoceramic and nanohybrid composite resins are almost the same.

\section{AUTHORS' CONTRIBUTIONS}

All the authors have contributed equally.

\section{CONFLICTS OF INTEREST}

The authors declare no conflicts of interest.

\section{FUNDING}

Nil.

\section{REFERENCES}

1. Lee IB, Cho BH, Son HH, Um CM. A new method to measure the polymerization shrinkage kinetics of light cured composites. J Oral Rehabil 2005;32:304-14.

2. Giachetti L, Russo DS, Bambi C, Grandini R. A review of polymerization shrinkage stress: Current techniques for posterior direct resin restorations. J Contemp Dent Pract 2006;7:1-14.
3. Sandelin B, Afaag A. Polymerization Shrinkage of Dental Composites Registered by a Video-imaging Device. A Pilot Study. Available from: https://www.pdfs.semanticscholar. org/2a49/556edee9d78c1701c4d798a91821ba168de7.pdf.

4. Hamouda IM, Elkader HA, Badawi MF. Microleakage of nanofilled composite resin restorative material. J Biomater Nanobiotech 2011;2:329-34.

5. Dentsply. Ceram X Universal and Duo; 2015. p. 27. Available from: https://www.google.com/search?q=5.+dents ply. + ceram $+x+$ universal + and + duo. $+2015 \% 3$ b2 $7 . \& o q=5 . \% 09$ dentsply. + ceram $+x+$ universal + and + duo.$+2015 \%$ 3 b27.\&aqs $=$ chrome 69 i57.3935j0j8\&sour ceid $=$ chrome \&ie $=$ utf- 8

6. Braga RR, Ferracane JL, Health O. Alternatives in polymerization contraction stress management. Crit Rev Oral Biol Med 2004;15:176-84.

7. Emeritus D. Philip's Science of Dental Materials. $12^{\text {th }}$ ed. United States: Elsevier, Saunders; 2013.

8. Dennison DG. Polymerization shrinkage and depth of cure of bulk fill flowable composite resins. Oper Dent 2014;39:441-8.

9. Sarangi P, Satapathy SK, Mohanty S, Mallick R, Behera S, Nanda SR. An in-vitro evaluation of microleakage among nano ceramics and nano hybrid composite resins in Class V cavities. Sci J Dent 2014;1:14-8.

10. Kim HJ, Park SH. Measurement of the internal adaptation of composite resins using micro-CT and its correlation with polymerization shrinkage. Oper Dent 2014;39:E57-70.

11. Enone LL, Awotile AO, Adegbulugbe CI, Agbaje LO, Odogun LA, Oyapero A. One-year clinical evaluation of nanohybrid composite resin in the restoration of occlusal and proximo-occlusal cavities in Nigeria. Adv Hum Biol 2017;7:130-6.

12. Suhasini K, Madhusudhana K, Suneelkumar C, Lavanya A, Chandrababu KS. Clinical performance of Class I nanohybrid composite restorations with resin-modified glass-ionomer liner and flowable composite liner : A randomized clinical trial. J Conserv Dent 2016;19:510-5.

13. Julian D, Amit M, Karin V, David C. Effect of resin-composite filler particle size and shape on shrinkage-stress. Dent Mater 2012;28:609-14. 